\title{
Q: varia
}

\section{Pedro Nieto Montañés y la escultura del protobarro- co sevillano: una nueva aportación al catálogo de su obra}

\author{
Sergio Ramírez González \\ Universidad de Málaga
}

Por fortuna, la investigación referente a piezas artísticas de la Edad Moderna no deja de concedernos alguna que otra sorpresa, cuando se ha traspasado ya el umbral que nos introduce en pleno siglo XXI. Pese a considerarse que no resta nada por descubrir al respecto, una profunda revisión de los documentos históricos depositados en los archivos, un efectivo trabajo de campo donde se rastree su trayectoria $y$, por qué no decirlo, una buena dosis de suerte siempre necesaria en estos casos pueden acabar dando unos frutos satisfactorios, que ayudarán a sacar del anonimato a los artífices de esculturas, pinturas y artes decorativas. Claro está, para iniciar este proceso se necesita estar en posesión de un "testigo" clave, cuyo testimonio -ya sea material o gráfico- impulse a decantarnos hacia una de las dos opciones que trazan este tipo de estudios. En resumidas cuentas, la dualidad abordada a la hora de documentar una obra es la que nos obliga, por un lado, a partir del objeto en sí como punto de referencia para alcanzar la certificación escrita, o bien, la que nos lleva a dar desde los datos impresos y manuscritos con una prueba física localizada en un inmueble concreto. Esta segunda opción ha sido la continuada en la búsqueda de una escultura de Crucificado procedente del antiguo monasterio de Santa María Magdalena de Antequera ${ }^{1}$, perfectamente datada en el tiempo y ejecutada por el escultor sevillano Pedro Nieto Montañés.

Como casi siempre, en este tipo de trabajos, los datos puntuales de referencia llegaron a nuestras manos por casualidad, dentro, eso sí, de una amplia investigación que desde años atrás nos ha llevado a recopilar la documentación necesaria acerca de los conventos franciscanos de Málaga y provincia, hoy felizmente plasmada en una Tesis Doctoral ${ }^{2}$. Pero más que un indicio propiamente dicho, la consulta de los impresos ofrecía la información ya anunciada con todo lujo de detalles. El estudio de la historia del convento o desierto de penitencia antequerano hizo que nos trasladásemos hasta el Archivo Franciscano Ibero-Oriental de Madrid, con el propósito de consultar uno de los pocos ejemplares que aún existen sobre la crónica de franciscanos descalzos de la provincia de San Pedro de Alcántara, que escribiera Ginés García Alcaraz en 1761. Este libro fue justamente el que vino a facilitar tan

* RAMÍREZ GONZÁLEZ, Sergio: "Pedro Nieto Montañés y la escultura del protobarroco sevillano: una nueva aportación al catálogo de su obra",Boletín de Arte n 28, Departamento de Historia del Arte, Universidad de Málaga, 2007, págs. 619-628. 
valiosas reseñas, de ahí que nos pusiéramos manos a la obra para averiguar si aún existía la escultura, algo poco probable a tenor de la dispersión de obras que sufrió el edificio en el siglo $\mathrm{XIX}$, tras la Exclaustración de los religiosos y la posterior Desamortización de sus bienes. A la vez, crecian las dudas en el sentido opuesto sobre el hecho de que una imagen de tan renombrada devoción hubiera sido vendida o depositada en otro templo allende Antequera.

La clave del asunto la aportaron ciertos autores de la historiografía local, los cuales se hicieron eco de los informes relativos al traslado de las piezas más significativas -en una fecha aún sin determinar- desde el mismo cenobio alcantarino a la parroquia de San Miguel de Antequera ${ }^{3}$. En efecto, éste fue el destino de las magníficas

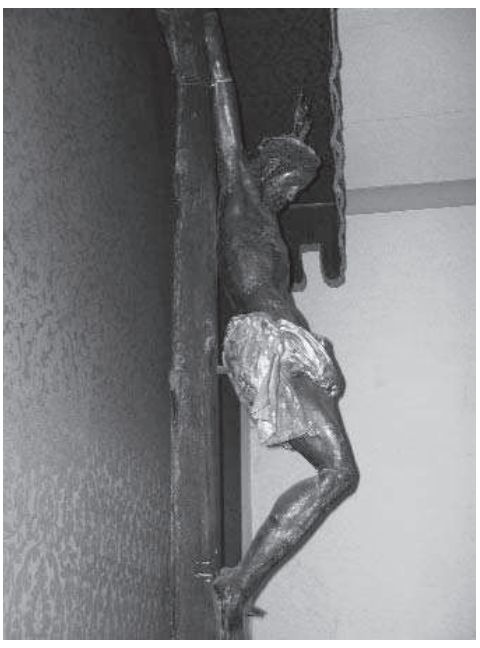

1. Crucificado de las Penas. Parroquia de San Miguel (Antequera, Málaga). esculturas de San Francisco de Asís,

según la visión de Nicolás $V$, de Pedro de Mena 4 , y la Magdalena penitente atribuida a Pablo de Rojas, ambas depositadas de unos años a esta parte en el Museo Histórico Municipal. La misma suerte corrió el que podemos denominar con toda propiedad como Cristo de las Penas, localizado en la última capilla del lado de la Epístola correspondiente al Sagrario- de este céntrico templo. Sin duda alguna, los apuntes recogidos acerca de su procedencia y, sobre todo, las particularidades formales y estilísticas de la escultura en cuestión, nos ofrecen la absoluta certeza de que se trata ,efectivamente, del Crucificado que modelara a mediados del Seiscientos el artista sevillano Pedro Nieto Montañés.

1 CAMACHO MARTÍNEZ, R.: "Locus eremus. El convento alcantarino de la Magdalena, en Antequera, desierto de penitencia", en PELÁEZ DEL ROSAL, M. (dir.): El franciscanismo en Andalucía, V y VI Curso de Verano (I) San Francisco en la Cultura y en la Historia del Arte español, Córdoba, Cajasur, 2001, págs. 43-62.

2 RAMíREZ GONZÁLEZ, S.: Málaga Seráfica. Arquitectura, patrimonio y discurso simbólico de los conventos franciscanos (1485-1835), Tesis Doctoral (inédita), Universidad de Málaga, 2006.

3 Cfr. FERNÁNDEZ, J. M.: Las iglesias de Antequera, Antequera, Biblioteca Antequerana, 1970; ROMERO BENITEZ, J.: Guía artística de Antequera, Antequera, Caja de Ahorros, 1989.

4 ROMERO TORRES, J. L.: "San Francisco de Asís. Pedro de Mena y Medrano", en SÁNCHEZ-LAFUENTE GÉMAR, R. (coord.): El esplendor de la memoria. El Arte de la Iglesia de Málaga, Málaga, Junta de AndalucíaObispado, 1998, págs. 180-181 y RAMÍREZ GONZÁLEZ, S.: "Pedro de Mena. San Francisco de Asís sobre e sepulcro", en HENARES CUÉLLAR, I. y LÓPEZ GUZMÁN, R. (coors.): Antigüedad y Excelencias, Sevilla, Junta de Andalucía, 2007, págs. 390-391. 
Varia Pedro Nieto Montañés y la escultura del protobarroco sevillano...

\section{ANTECEDENTES HISPALENSES DEL ESCULTOR: SU OBRA CONOCIDA.}

El desconocimiento casi absoluto de su vida y la escasez de datos referentes a su producción escultórica, hacen de este autor un personaje ciertamente enigmático del que aún podemos recibir múltiples sorpresas, en función de una calidad artística contrastada que difundió al resto de Andalucía desde el principal centro de elaboración regional de esta modalidad plástica. No en balde, Pedro Nieto debió nacer en la capital hispalense a finales del siglo XVI o principios del XVII, formándose desde muy joven en el taller del afamado escultor Francisco de Ocampo y Felguera (1579-1639). Este último adquirió sus principales conocimientos de la mano de su maestro Juan Martínez Montañés, sin desdeñar las virtudes reconocidas en su compañero Juan de Mesa y familiares de la talla de Andrés de Ocampo. Tan variada influencia le llevaron a mostrar en sus obras -sobre todo en las de tipo procesionalun estilo algo ecléctico, en el que prevalecen las pautas manieristas ejemplificadas en imágenes como la del Cristo del Calvario (Sevilla, 1612) y el Nazareno de la iglesia de San Bartolomé de Carmona, entre otras muchas. Sería precisamente en estas fuentes, donde bebió desde el punto de vista artístico Pedro Nieto durante los años de aprendizaje junto a otro de los escultores de la primera mitad del siglo XVII, Jacinto Pimentel, en ocasiones también "olvidado" por la crítica especialista. No obstante, la producción de Pimentel se encuentra algo más estudiada tanto en su etapa sevillana como gaditana. Su evolución del manierismo al barroco, y la movilidad mostrada por tierras andaluzas, le afectaron a la hora de imprimir un estilo muy personal a sus obras. Iniciado en la factura de retablos y coros en la provincia de Sevilla, su pronunciamiento en la imaginería procesional se desarrolló con mayor extensión en Cádiz a partir de que ejecutara -en opinión del investigador Francisco Espinosa de los Monteros- el Cristo de la Humildad y Paciencia, la Virgen del Carmen, el Señor de la Columna y el Cristo de la Expiración, de Cádiz, y la Virgen de la Confortación de Jerez de la Frontera.

Podemos aseverar, por tanto, que era éste el ambiente y círculo profesional más cercano en el que se movió Pedro Nieto, de quien se han obtenido noticias documentadas que fluctúan en el intervalo de 1610-1648 y siempre en el ámbito de la capital hispalense. Tan restringido periodo se altera al presente con este nuevo descubrimiento, pues el encargo para la ermita de la Magdalena de Antequera dilata y amplía algo más allá de lo conocido hasta ahora el ámbito cronológico de su actividad, amén del radio de acción geográfico extendido hasta el corazón mismo de la provincia de Málaga. A juzgar por las obras de las que se tiene referencia que ejecutara, parece ser que se especializó en imágenes de pasta con todo el riesgo que ello supone en el resultado estético y práctico final de este tipo de creaciones. Entre las primeras piezas conocidas se sitúan los Ladrones Dimas y Gestas (1628) para la Hermandad de Montserrat. Ambas imágenes se insertan en el paso de misterio de la Cofradía junto al Crucificado que tallara Juan de Mesa en 1619, representando de esta manera el momento de la Conversión del Buen Ladrón ${ }^{5}$. A estos ejemplos, 
habría que añadir el del Crucificado existente hasta 1936 en la parroquia de San Gil y que hiciera para la antigua Cofradía de Nuestra Señora de la Esperanza. Dicha corporación se fundó en 1595 en el convento de San Basilio -collación del Omnium Santorum- y no fue hasta pocos años después, el 26 de febrero de 1630, cuando concertó con Pedro Nieto la hechura de su titular. A tenor de estas fechas, es de suponer que la escultura se viera envuelta en el traslado que emprendió la institución en 1653 con destino a la iglesia de San Gil, donde pasó a compartir la titularidad con el Señor de la Sentencia $(1654)^{6}$. En realidad, se tiene constancia de que el Crucificado de Pedro Nieto procesionó de forma continuada con la Virgen de la Esperanza (Macarena) hasta 1693, quedando en depósito a partir de entonces en la capilla de los pies del templo. Su destrucción se debió al incendio provocado en el edificio durante los sucesos de la Guerra Civil7.

Poco después, en 1632, este mismo escultor modeló una imagen de bulto redondo en pasta policromada para la actual Hermandad de San Isidoro, coincidiendo -justo es decir- con sus inicios institucionales. Se trataba, pues, del principal titular de la corporación, el Cristo de las Tres Caídas, que fue sustituido en 1668 por el que todavía existe ejecutado en el taller de Alonso Martínez. La obra de Nieto podría verse procesionar aún hoy día, si no fuera por esas circunstancias curiosas y algo rocambolescas que con tanta frecuencia se producían en la época. El caso es que la institución de referencia surgió en la parroquia de Santiago, en la que desarrolló sus cultos y principales cometidos durante buena parte del siglo XVII. Los problemas sobrevinieron sobre ella cuando, tras tres décadas de estancia continuada en el lugar, decidió trasladar su residencia canónica a la iglesia de San Isidoro. El 17 de abril de 1668, ya preparados para emprender la marcha, el párroco de Santiago montó en cólera ante semejante decisión y no tuvo otra idea que impedir la salida de la imagen del Cristo de las Tres Caídas, sujetando una viga a su peana con cadena y candado. Conscientes de la escasa solución del asunto, los hermanos decidieron continuar sin la escultura y dejarla en depósito a un feligrés a cambio de mil doscientos cincuenta reales, que les sirvieron para encargar una nueva a Alonso Martínez. Por suerte, la primitiva imagen se conserva custodiada en la casa-hermandad de la cofradía de San Isidoro.

Por último, las noticias de piezas realizadas por Pedro Nieto, en esta ocasión atribuidas con bastante fundamento, nos acercan al misterio del Descendimiento (1633) que hizo para la Hermandad sevillana de la Quinta Angustia. Aparte del Crucificado que efectuó Pedro Roldán en 1659, el resto de imágenes de tan espec-

5 Debido a su mal estado de conservación, ambas esculturas fueron sustituidas en 1981 por otras de Gabriel Cuadrado hasta que se restauraron en 1997.

6 LÓPEZ MARTíNEZ, C.: "La Hermandad de Nuestra Señora de la Esperanza de San Gil y el escultor Pedro Nieto", Calvario, Sevilla, 1950, s/p.

7 Como recuerdo de esta vinculación, en 2006 la Hermandad de la Macarena ha encargado al escultor Fernando Murciano Abad una reproducción de pequeñas dimensiones del antiguo titular, a colocar en una cruz alzada que procesionará en la estación de penitencia de la madrugada del Viernes Santo. 
tacular representación se han asignado tradicionalmente al buen hacer de nuestro escultor, salvo la efigie de la Virgen de la Quinta Angustia que talló en 1932 Vicente Rodríguez Caso. Con todo, esta última sustituyó a otra anterior también de Nieto que estuvo procesionando hasta 1931, cuando por razones que desconocemos -algo polémicas por cierto- se retiró del culto público para guardarla en las dependencias de la Hermandad. En definitiva, el vigente grupo escultórico atribuido a Pedro Nieto lo componen los Santos Varones Nicodemo y José de Arimatea, San Juan Evangelista, María Magdalena y las dos Marías, aunque recientemente se tiende a considerar estas esculturas como salidas de manos de Pedro Roldán.

\section{El convento de la Magdalena y el Crucificado antequerano.}

El monasterio franciscano de la Magdalena -a las afueras de Antequera, en la carretera del Valle de Abdalajís- tiene sus orígenes más remotos en el complejo eremítico que fundara en 1570 el mercader Alonso Álvarez de Tejada, quien presionado por las deudas de su negocio decidió retirarse al campo para vivir en soledad y penitencia, acompañado sólo con una pintura de Santa María Magdalena. La reputación adquirida en sus continuas mendicaciones por la ciudad, originó que le siguieran numerosos adeptos ávidos por compartir sus mismas experiencias. De este modo, se conformó un grupo compacto de más de diez personas organizado bajo la maestría del ya denominado hermano Alonso de Jesús. Ocupando cuevas naturales y diversas ermitas allí construidas, entre ellas la de la Magdalena, los anacoretas dedicaron su vida a desempeñar labores manuales y agrícolas imbuidas por un ambiente de soledad que complementaban con ayunos, oraciones y penitencias. Con el paso de los años, los miembros de esta comunidad fueron adquiriendo nuevos privilegios diocesanos, que le llevaron a ser pronto uno de los centros devocionales más importantes de la zona.

La fama de este eremitorio se extendió pronto por toda Andalucía, merced a los presuntos prodigios que se realizaron por intercesión de su titular. Ya resonaban en Sevilla estos portentosos ecos, cuando la epidemia de 1648 infectó con rapidez a una cantidad considerable de sus ciudadanos. Entre ellos, cayó contagiado el Padre Cárdenas -venerable sacerdote de la parroquia de San Pedro-, quien consciente del peligro que corría su vida hizo voto de visitar personalmente el santuario de la Magdalena y costearle una alhaja a elegir por los ermitaños, si llegaba a recuperar su maltrecha salud. Lo sorprendente del caso es que apenas había acabado de pronunciar la promesa, se halló sano de repente ante la admiración de los presentes que esperaban su muerte de un momento a otro $y$, aún, tuvo fuerzas para viajar a los pocos días a la localidad de Antequera. Una vez personado en el santuario, comunicó sus intenciones a los ermitaños acerca de costear la pieza que les pareciese más conveniente para el aderezo del templo. Después de discutir largo y tendido sin alcanzar un dictamen conjunto, convinieron en tomar la decisión más acertada por medio de la oración. 
Para este fin, se congregaron todos en la iglesia y mientras trataban de resolver las dudas personales, el Padre Cárdenas interrumpió el silencio que invadía el espacio, diciendo que se le había ocurrido hacer donación de una imagen de Cristo Crucificado por ser tan propia [sic] de una iglesia, que tenía por Titular aquella tan afortunada Penitente, que el mismo Soberano prototypo celebró de amante. La propuesta fue bien recibida por todos los ermitaños y, así, se determinó que Juan Portillo de Grijalba y el hermano Diego de Jesús lo acompañasen hasta la ciudad hispalense escoltando a su vuelta la sagrada imagen ${ }^{8}$. Realizada, según las fuentes, por un escultor apellidado Nieto -que no es otro que Pedro Nieto-, la pieza escultórica llegó al templo antequerano procedente de Sevilla el 13 de septiembre de 1650 y un día después -festividad de la Exaltación de la Cruz- se celebró su colocación junto a la Magdalena con gran alborozo de los eremitas y vecinos de Antequera, en tanto se le confería la advocación del Santo Cristo de las Penas. Pese a no desvelar una consumada perfección artística, la escultura despertó desde el primer momento una enorme devoción en toda la comarca demostrada en las constantes promesas y las romerías que se le brindaban anualmente:

"Aunque el simulacro no está formado con aquellos lastimosos quebrantos, con que suelen efigiarse otros, es devotíssimo; porque muestra en el semblante una tan dulce, y magestuosa ternura, que mueve a singulares afectos de asombro, amor y veneración, aún a quien le registra de passo".

Tal es así, que el Obispo fray Alonso de Santo Tomás concedió cuarenta días de indulgencias a quienes rezasen el Credo delante de ella9 ${ }^{9}$.

Tan numerosas fueron las maravillas que obró esta imagen que ya por comunes perdieron para el vulgo su carácter milagroso. El mejor ejemplo de ello se manifestó en los múltiples exvotos que dejaron los fieles depositados en el Santuario de la Magdalena, en forma de obsequios diversos y pinturas donde se representaban los episodios extraordinarios. Fue tal la fama conseguida por esta imagen que, el 25 de abril de 1673, Clemente $X$ concedió indulgencia plenaria durante siete años a los fieles que visitasen la iglesia el día de la Exaltación de la Cruz e Inocencio XI la confirmó por otros siete en julio de $1679^{10}$. Aprovechando el cambio de rumbo que produjo el nuevo Crucificado, los ermitaños intentaron perfeccionar sus costumbres con la creación de unos estatutos reformados, que aprobó verbalmente el Obispo Diego

8 GARCÍA ALCARAZ, G.: Segunda parte de las Chrónicas de la Santa Provincia de San Pedro de Alcántara, de Religiosos Menores Descalzos de la más estrecha Regular Observancia de N. P. S. Francisco, en los reynos de Granada, y Murcia, Murcia, Nicolás Villargordo y Alcaraz, 1761, pág. 359.

${ }^{9}$ Archivo Histórico Municipal de Antequera (AHMA), Historia de Antequera de Francisco Barrero Baquerizo

(Ms), 1732, fol. 437v.
10 VILLEGAS RUIZ, M.: "El convento de la Magdalena de los franciscanos descalzos de Antequera, según una crónica latina del siglo XVIII", en PELÁEZ DEL ROSAL, M. (dir.): El franciscanismo en Andalucía, $V$ y V Curso de Verano (II) San Francisco en la Cultura y en la Historia del Arte español, Córdoba, Cajasur, 2002, pág. 424. 


\section{- Varía Pedro Nieto Montañés y la escultura del protobarroco sevillano...}

Martínez de Zarzosa y se confirmaron en 1659 con los autos jurídicos presentados por el Provisor Alonso Gutiérrez de Montalvo. Con la desaparición de los promotores y sus inmediatos seguidores, el grupo se fue nutriendo de otros anacoretas más relajados en sus costumbres. Poco a poco, a la virtud de la abstinencia le sucedió la concupiscencia, al ayuno la glotonería y a los ejercicios de penitencia la pereza y la ociosidad, presentándose unas nuevas generaciones colmadas de vicios y faltas de buenas costumbres. Además, las romerías se celebraban con tal profanidad e indecencia que las cuevas que habian sido durante años casa de oración se convirtieron en "cuevas de ladrones", en expresión de los testimonios de época. La propagación de estos hechos llegó pronto a los oídos de fray Alonso de Santo Tomás, quien no dudó ni un momento en desplazarse

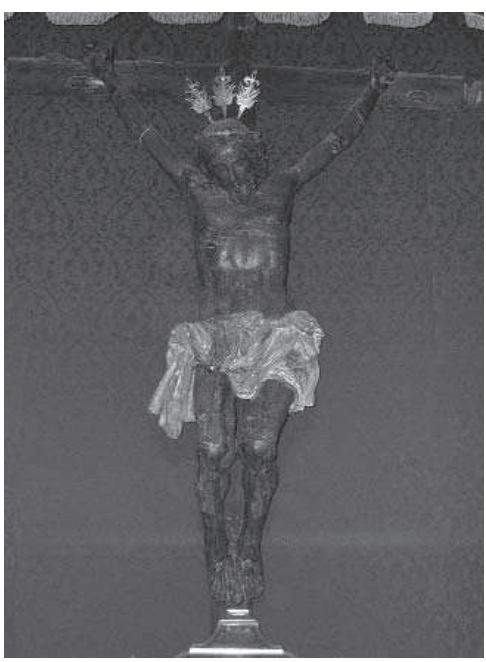

2. Crucificado de las Penas. Parroquia de San Miguel (Antequera, Málaga). personalmente hasta la ermita para informar y recriminar a sus moradores las faltas y desacatos que estaban ejecutando ${ }^{11}$

Una vez comprobado por el Prelado que la corrupción había invadido aquel instituto místico, ordenó desterrar a todos sus componentes y retirar del lugar el Sacramento del Sagrario. Mientras tanto, el Prelado dejó en el lugar a un par de eremitas de su confianza, a la espera de asignar un grupo de religiosos que vinieran con una organización mucho más consolidada. Con estos precedentes, en 1686 se ofreció vía libre para la instauración en el lugar de un monasterio -también dedicado a Santa María Magdalena- perteneciente a la Orden Franciscana Descalza e inserto en la jurisdicción seráfica de San Pedro de Alcántara.

Desde entonces y hasta la exclaustración de los religiosos en 1835, el Crucificado de Pedro Nieto continuó presidiendo junto a la Magdalena el altar mayor del templo alcantarino, caracterizado por la celebridad que le confirieron los innumerables milagros cumplidos.

Esta popularidad, unida a la incuestionable calidad artística de la pieza, fue la responsable de que las autoridades pertinentes decidieran hacerse con la escultura para custodiarla, de forma más segura, en el templo de San Miguel de Antequera.

11 GARCÍA ALCARAZ, G.: op. cit., pág. 360. 
VALORACIÓN ARTISTICA DE LA OBRA.

La pieza objeto de estudio, representación de Jesucristo crucificado ya muerto, se revela ante el espectador con unas características plásticas y estéticas que pueden resultar algo toscas a simple vista. Este hecho es debido al material con que se encuentra realizada la obra, pasta de madera, siendo una de las particularidades del autor, común a buena parte de su producción actualmente conocida. Por ello, no es de extrañar que aquellas partes del cuerpo que necesitan de una mayor estilización y minuciosidad, en el caso de los brazos y piernas, se definan a raíz de una aparente falta de delicadeza en el modelado que les hace mostrarse con cierta rigidez y desproporción. Se trata, pues, de un Crucificado que todavía combina las pautas esenciales de la escultura barroca con peculiaridades de la estética manierista adquiridas a través de su maestro Francisco de Ocampo, y provenientes en última instancia de Juan Martínez Montañés. Así, al canon alargado de la figura y la imperturbable serenidad del rostro, se contraponen otros aspectos más realistas como la profusión de sangre y hematomas a lo largo de la superficie corpórea y la confusa disposición del paño de pureza. Otra de las singularidades responde al hecho de que se encuentra fijado a la cruz con cuatro clavos, tal como lo viera Santa Brígida de Suecia en sus revelaciones y continuando los dictámenes que ya había ofrecido el pintor y tratadista hispalense Francisco Pacheco ${ }^{12}$.

En realidad, lo que hace Pedro Nieto con la escultura antequerana es simplificar la disposición de las piernas respecto al prototipo del Cristo de la Clemencia y, de esta forma, lejos de cruzar ambas extremidades las dispone en paralelo, a la misma altura y avanzando levemente la planta del pie derecho sobre el izquierdo. Con esto último, y el lógico arqueamiento que produce el avance de las rodillas, se logra romper el rígido hieratismo que suelen exponer las crucifixiones con cuatro clavos, a decir verdad más numerosa en pintura que escultura. En rasgos generales, la morfología de la pieza "cristífera" se encuentra supeditada al patente descolgamiento del cuerpo en la cruz arbórea, debido al estado de relajación y laxitud propia de quien acaba de expirar. A tenor de estos precedentes, el artífice de la obra acentúa tales aspectos juntando todo lo posible las manos en la horizontal del patibulum y trazando unas pronunciadas diagonales con los brazos, que hacen concentrar la resistencia y gravedad corporal en los omóplatos. Como consecuencia, la figura del Crucificado esboza en su perfil una perceptible línea en forma de "s", que se fundamenta en un contorno cóncavo constituido por la inclinación de la cabeza y el encorvamiento de la espalda, seguido de otro convexo facilitado por el avance de las caderas y rodillas. Por lo demás, nos hallamos ante una escultura de un correcto tratamiento anatómico y un modelado más que aceptable, pese a carecer de la pulcritud habitual en las imágenes ejecutadas en madera. Bien es cierto, en este sentido, que

12 Cfr. PACHECO, F.: El arte de la pintura, (edición, introducción y notas a cargo de B. BASSEGODA i HUGAS), Madrid, Cátedra, 1990. 


\section{- V Varía Pedro Nieto Montañés y la escultura del protobarroco sevillano...}
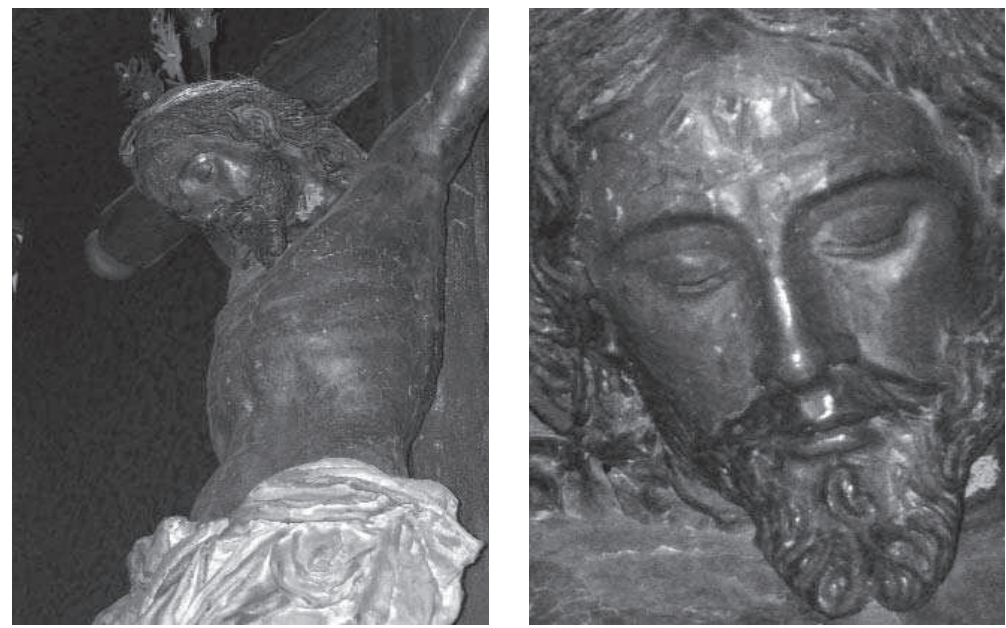

3. Crucificado de las Penas (detalle) PEDRO NIETO.

4. Crucificado de las Penas (detalle). PEDRO NIETO.

si la caja torácica muestra un excelente trabajo en cuanto al estudio del componente óseo y muscular, los brazos y piernas se representan más descuidadas al respecto y hasta con un evidente punto de desproporción y sumario tratamiento. Más sorprendente es la disposición de las manos, aquí muy esquemáticas, severas y sin naturalismo alguno. Este efecto se intensifica en las extremidades inferiores a través del insuficiente volumen conferido a rodillas y pies -dotados de una enorme planitudsiendo por consiguiente más adecuada la vista lateral que la frontal de la obra. Pero si algo debe destacarse en esta pieza seiscentista es la resolución de la cabeza, muy similar a la que confirió al antiguo Crucificado de la parroquia de San Gil.

Apoyada sobre el hombro derecho, expone unas características estéticas que se aproximan -más bien continúan- la impronta reflejada en la producción "cristífera" de Juan Martínez Montañés, con el Cristo de la Clemencia

como principal modelo, después patentizadas por Juan de Mesa en el Cristo de la Buena Muerte y por Francisco de Ocampo en el Cristo del Calvario, entre otros ejemplos.

Nos referimos principalmente a un rostro de facciones relajadas que transmite paz y serenidad a través de la dulcificación de los rasgos, cuestión que también enfatiza el autor en las imágenes femeninas de la Magdalena y las dos Marías del misterio de la Quinta Angustia. De hecho, los vestigios del dolor solo se perciben en 
los restos de sangre de la frente producidos por las heridas de una corona de espinas que no posee. Por lo demás, las leves arrugas del entrecejo no alteran en absoluto la suavidad del gesto, conseguida con la aplicación de volúmenes redondeados y aristas curvas como las que perfilan las cejas. La reposada boca se complementa con unos ojos almendrados que se cierran prácticamente para dejar entrever las pupilas inertes. El óvalo facial -de cierta estilización- se complementa con una barba bífida y se enmarca mediante una cabellera de subrayados mechones, que se peina con raya central y cae en los hombros dejando al descubierto los pabellones auditivos. Menos depurada se revela la técnica del autor a la hora de modelar el paño de pureza. La gran cantidad de pliegues y el solapamiento de éstos sin un orden concreto, le ofrecen una apariencia de volumen tosco y plano resuelto torpemente en el recogido de la cadera derecha. Las huellas del realismo barroco quedan patentes en una policromía definida por los rastros de la tortura, de ahí que se destaquen los moratones de las articulaciones y los abundantes restos de sangre que se reparten por todo el cuerpo, con especial repercusión en las heridas de las cinco llagas. De todas ellas, la del costado es la que más impacto produce sobre el espectador al prolongar esta señal hasta la rodilla, traspasando con creces el obstáculo del sudario.

En la actualidad, la escultura de referencia se encuentra en un pésimo estado de conservación no sólo por la suciedad acumulada que desvirtúa la policromía original, sino también y sobre todo por los problemas de estabilidad que provocan las fisuras y grietas localizadas en las extremidades superiores e inferiores. Si a ello añadimos la inconsistencia del material utilizado en la pieza, la situación se agrava aún más si cabe requiriendo de una pronta restauración a efectuar por manos expertas. 